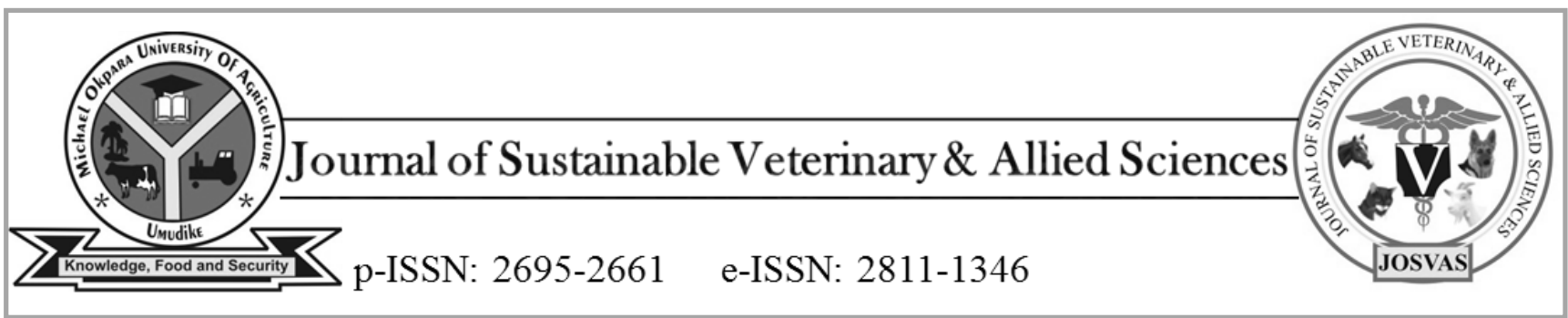

JoSVAS 2021, Vol 1, Issue 1: 41-46

C2021 College of Veterinary Medicine,

Michael Okpara University of Agriculture, Umudike, Nigeria

Original Research Article

\title{
Diminazene aceturate-concentrations in tissues of dogs co-treated with oxtetracycline long acting \\ ${ }^{1}$ *Onyeachonam, F.O., ${ }^{2}$ Onyeyili, P.A., ${ }^{2}$ Saganuwan, A. S. \& ${ }^{2}$ Agbo, O.J. \\ ${ }^{I}$ Department of Veterinary Biochemistry and Animal Production, Michael Okpara University of Agriculture, Umudike, ${ }^{2}$ Department of Veterinary Pharmacology and Toxicology, Federal University of Agriculture, Makurdi, Nigeria
}

Corresponding author: pleasfavo@gmail.com. +2347053638305

\begin{abstract}
Diminizene aceturate (DA) is the drug of choice for treating Canine Trypanosomosis and Canine Babesiosis in many countries of the world. However, co-administration of the drug with long acting Oxytetracycline (OXY-LA) has been associated with nervous signs suggestive of its toxicity, in treated dogs, even at the normal dose. To investigate what causes this toxicity, fourteen Nigerian indigenous dogs were randomly selected into two groups that comprised six dogs each and the remaining untreated two dogs were used for preparation of tissue standards. One group was treated with DA ( $3.5 \mathrm{mg} / \mathrm{kg})$ alone while the other was, additionally, treated with OXY-LA, 10 minutes post treatment (PT) with DA. Two dogs from each group were sacrificed at 240, 360 and 480 hours, PT and their livers, brains, kidneys, hearts and skeletal muscles were harvested and assayed for DA. Mean DA-concentrations in brains of the DA-OXY-LA group $\left(19.71 \pm 1.31^{\mathrm{a}} ; 15.86 \pm 2.96^{\mathrm{a}} ; 9.11 \pm 3.31^{\mathrm{a}}\right)$ were higher $(\mathrm{P} \leq 0.05)$ than $1.39 \pm 0.45^{\mathrm{b}} ; 1.05 \pm 0.29^{\mathrm{b}} ; 0.71 \pm 0.30^{\mathrm{b}}$ of the DA-alone group at 240,360 and 480 hours, PT, respectively. Also, mean-DA concentration in kidneys $\left(8.00 \pm 0.46^{\mathrm{a}}\right)$ of the DA-OXY-LA group was significantly $(\mathrm{P} \leq 0.05)$ higher than $3.76 \pm 0.32^{\mathrm{b}}$ of the DA-alone group at 360 hours PT. These results suggest that OXY-LA enhances DAaccumulation in the brain and reduces its kidney-elimination, thus making the normal dose to act as overdose, which causes the nervous signs often manifested by treated dogs.
\end{abstract}

Keywords: Co-administration, diminazene aceturate, dogs, elimination half-life, oxytetracycline long acting

\section{INTRODUCTION}

Diminazene aceturate (Berenil $®$ ) has been the drug of choice for treatment of animal trypanosomosis since 1955 . It is an aromatic diamidine consisting of two amidinophenyl moieties linked by a triazene bridge (Peregrine \& Mamman, 1993). In addition to its trypanocidal activity, Berenil ${ }^{\circledR}$ also has excellent anti-bacterial activity (Rashid et al., 2008). Although, the compound has been in use for more than half a century, the exact mechanism of action and its effect on the host immune system are still poorly understood. Some studies suggest that the compound binds to trypanosomal kinetoplast DNA in a non-intercalative manner through specific interaction with sites rich in adenine- thymine base pairs (Gonzalez et al., 1997). This causes irreversible damage resulting in the development of akinetoplast parasites (Brack et al., 1972; Riou \& Bernard, 1980).
Additionally, Berenil induces condensation of heterochromatin during the G2 phase of cell cycle, which causes the DNA to become completely unfolded (Haaf et al., 1989). Berenil also alters the confirmation of DNA by interfering with binding of DNA topoisomerases (Poot et al., 1990).

Oxytetracycline long acting (OXY-LA), a tetracycline derivative obtained from Streptomyces rimosus, is a broadspectrum antibiotic used against a variety of pathogens, including bacteria, mycoplasma, rickettsia, chlamydiae and even some protozoa (Bywater, 1991). Oxytetracycline long acting is a bacteriostatic antibiotic that inhibits protein synthesis by reversibly binding to the $30 \mathrm{~S}$ ribosomal subunit of susceptible organisms (Chopra \& Roberts, 2001). The antibacterial efficacy of OXY-LA is described as timedependent. It is distributed rapidly and extensively in animal 
body fluids and tissues, undergoes enterohepatic recirculation in some mammals and is then excreted primarily by glomerular filtration and biliary elimination (Adir, 1975). The term "long-acting" implies that the formulation provides a prolonged circulation of antibacterial concentrations of the active agent and shows a commensurate improvement in clinical efficacy (Escudero et al., 1994).

It is a common Veterinary practice to administer diminazene aceturate (DA) and Oxytetracycline long acting (OXY-LA) concurrently to dogs in order to treat protozoan diseases such as trypanosomosis, and babesiosis and to prevent secondary bacterial infections respectively. Since trypanosomosis for instance is associated with immune deficiency which prone the body system of the infected animal to secondary bacterial invasion, hence the two drugs are given concomitantly. Clinically, some dogs when so treated dogs, show signs of toxicity such as tremor, nystagmus, ataxia, spasms, uncoordinated movements, vomiting and eventually death 23 days after intramuscular administration of diminazene aceturate (Bauer, 2006). This study may provide basis for recommending adjustment in dosage regimen of intravenous diminazene aceturate co-administered with oxytetracycline long acting and information on the possible withdrawal period of diminazene aceturate for dogs co-treated with oxytetracycline long acting and diminazene aceturate combination.

This study was conducted to determine the cause of these toxic effects, by evaluating the effects of oxytetracycline long acting on tissue kinetics of diminazene aceturate in healthy Nigerian indigenous dogs.

\section{MATERIALS AND METHOD}

\section{EXPERIMENTAL ANIMALS}

Fourteen (14) Nigerian indigenous dogs of similar age (4-6 months) and weight (4 to $5 \mathrm{~kg}$ ) were used. The dogs were obtained from Umudike and Aba metropolis in Abia state, South-East of the country. The dogs were housed under tickfree conditions for a 1-month period prior to the commencement of the study. Additional tick control was effected topically using Fipronil ${ }^{\circledR}$ and was done according to the manufacturer's instructions. Full clinical examinations such as full blood count and serum biochemistry test (ALT, ALP, urea, creatinine, albumin, globulin, $\mathrm{Na}^{+}, \mathrm{K}^{+}$and $\mathrm{Ca}_{2}^{+}$) were performed to confirm the animals' health status one day prior to the study. Teflon catheters were inserted in both femoral veins prior to commencement of the study. Animals were fed a commercial dog diet and had free access to water. The approval of animal ethics committee was sought and received from the Director Veterinary Teaching Hospital in Joseph Tarkar Sarwuan University, Makurdi before the study commenced.

\section{RECONSTITUTION OF DIMINAZENE ACETURATE (BERENIL@):}

A $7 \%$ DA solution was prepared according to the manufacturer's instruction and used for the investigation. A sachet of $1.05 \mathrm{gm}$ of DA and $13.95 \mathrm{ml}$ (15 minus $1.05 \mathrm{ml})$ of distilled water were mixed to get $7 \%$ Diminazene aceturate. The DA-solution was used immediately after preparation.

\section{DRUG ADMINISTRATION}

The dogs were separated into two groups (1 and 2) of 6 each. Diminazene aceturate was administered to group 1 through the left femoral vein with aid of a catheter at the dose of $3.5 \mathrm{mg} / \mathrm{kg}$ body weight using $7 \%$ solution. Oxytetracycline long acting was administered to group 2 at the right gluteal muscle, deep intramuscularly, at the rate of $20 \mathrm{mg} / \mathrm{kg}$ body weight, ten minutes after administration of Diminazene aceturate $(3.5 \mathrm{mg} / \mathrm{kg}$ body weight).

\section{SAMPLE COLLECTION:}

Two dogs from each group were sacrificed at 240 hours, 360 hours and 480 hours, post DA-treatment (PT). Samples of the liver, brain, kidneys, heart and skeletal muscle were harvested. Two other dogs (not treated with Diminazene aceturate) were sacrificed and their liver, brain, kidneys, heart and skeletal muscle harvested for preparation of tissue standards. All the tissue samples were placed in bags and stored at $-10^{\circ} \mathrm{C}$ until analyzed. The analysis was within 2 weeks of the sample collection.

\section{PREPARATION OF STANDARDS:}

Standard solution $(5 \mathrm{mg} / \mathrm{ml})$ was prepared by dissolving 250 $\mathrm{mg}$ of diminazene aceturate in $50 \mathrm{ml}$ of distilled water. From a diminazene aceturate stock solution of $5 \mathrm{mg} / \mathrm{mL}$ in Milli-Q water, serial dilutions were made as follows: $0.05 ; 0.1 ; 0.3$; $0.5 ; 0.7 ; 0.9 \mathrm{mg} / \mathrm{ml}$ to obtain a calibration curve.

\section{DETERMINATION OF DIMINAZENE ACETURATE RESIDUE}

Diminazene aceturate residue was determined using Perkin Elmer High performance liquid chromatography (HPLC) system with a Flexar UV/VIS Detector (Waltham, Massachusetts, USA) at $254 \mathrm{~nm}$. A $10 \mu$ l fixed injection loop was made in a Zorbax SB-C8 (München, Germany), column $(5 \mu \mathrm{m}, 150 \mathrm{~mm} \times 4.6 \mathrm{~mm})$ with a $0.5 \mathrm{ml} / \mathrm{min}$ flow mobile phase consisting of methanol-acetonitrile-Milli-Q water $(10: 10: 80 v / v / v)$, adjusted to $\mathrm{pH} 4$ with $100 \%$ formic acid (Astriku et al., 2002).

Diminazene assay Analysis was performed using a previously validated HPLC method (Miller et al., 2005). The plasma and tissue solution were purified by deproteinization. One millimeter each of tissue solution was vortexed for 20 seconds with half millimeter of $10 \%$ hydrochloric acid. Proteins were separated by centrifugation at $4000 \mathrm{rpm}$ for 10 min and the $\mathrm{pH}$ of the supernatant was neutralized at 7 with 4M Potassium hydroxide (Koshiishi et al., 1998). The 
resulting solution was transferred to HPLC vials and injected. Retention time for peak of interest was determined. Limit of quantification for diminazene in dog tissue samples were determined. Dog plasma fortified with standard of diminazene aceturate was used to validate the assay (DaSilva et al., 2009).

\section{STATISTICAL ANALYSIS}

Data on tissue kinetics presented as mean \pm SEM. Test for significance between the parameters in respect of diminazene aceturate alone and its combination with OXY-LA was performed using paired Student's t test. Least significant difference was detected at 5\% level of confidence (Daniel, 2010).

\section{RESULTS}

Means of concentrations of DA in the brain of dogs treated with DA and OXY-LA at 240 hours (Post treatment) PT, 360 hours PT and at 480 hours PT $\left(19.71 \pm 1.31^{\mathrm{a}}, 15.86 \pm 2.96^{\mathrm{a}}\right.$ and $\left.9.11 \pm 3.31^{\mathrm{a}}\right)$ were significantly higher $(\mathrm{P}<0.05)$ than $1.39 \pm 0.45^{\mathrm{b}}, 1.05 \pm 0.29^{\mathrm{b}}$ and $0.71 \pm 0.30^{\mathrm{b}}$ of $\operatorname{dogs}$ administered DA alone (Table I).

There was no significant difference $(\mathrm{P}>0.05)$ in concentration of DA in skeletal muscles of dogs treated with DA alone and in those treated with DA plus OXY-LA though concentrations of DA in the dogs administered DA plus OXY-LA $\left(17.65 \pm 0.26^{\mathrm{a}} ; 10.23 \pm 4.97^{\mathrm{a}}\right.$ and $5.85 \pm$ $2.65^{\mathrm{a}}$ ) were still slightly higher at 240 hours PT, 360 hours PT and 480 hours PT than $15.85 \pm 5.75^{\mathrm{a}} ; 8.01 \pm 2.39^{\mathrm{a}}$ and $5.65 \pm 3.80^{\mathrm{a}}$ of the dogs treated with DA alone. DA concentration in both groups decreased from 240 hours PT to 480 hours PT (Table II).

DA concentration in liver did not vary significantly $(\mathrm{P}>0.05)$ between the two groups but unlike in other tissues, means of the DA concentration in livers of dogs treated with DA plus OXY-LA $\left(8.58 \pm 0.54^{\mathrm{a}} ; 8.07 \pm 0.55^{\mathrm{a}}\right.$ and $\left.5.62 \pm 0.48^{\mathrm{a}}\right)$ were lower than $12.91 \pm 2.71^{\mathrm{a}}, 15.12 \pm 3.44^{\mathrm{a}}$ and $7.18 \pm 3.34^{\mathrm{a}}$ ) of the group treated with DA alone.

Also observed was that mean-DA in liver of the dogs treated with DA alone increased from $12.91 \pm 2.71$ at 240 hours PT to $15.12 \pm 3.44$ at 360 hours PT instead of decreasing and later

Table I. The average diminazene aceturate concentrations $(\mu \mathrm{g} / \mathrm{g})$ in the brain of dogs treated with diminazene aceturate $(3.5 \mathrm{mg} / \mathrm{kg})$ alone and diminazene aceturate plus oxytetracycline long acting (20mg/kg) combination.

\begin{tabular}{lll}
\hline & \multicolumn{2}{c}{ Concentration $(\mu \mathrm{g} / \mathrm{g})$} \\
Time & Diminazene & $\begin{array}{l}\text { Diminazene }+ \\
\text { Oxytetracycline } \\
\text { long acting }\end{array}$ \\
\hline 240 & $1.39 \pm 0.45^{\mathrm{b}}$ & $19.71 \pm 1.31^{\mathrm{a}}$ \\
360 & $1.05 \pm 0.29^{\mathrm{b}}$ & $15.86 \pm 2.96^{\mathrm{a}}$ \\
480 & $0.71 \pm 0.30^{\mathrm{b}}$ & $9.11 \pm 3.31^{\mathrm{a}}$ \\
\hline
\end{tabular}

Different superscript at same row shows significantly difference at $P<0.05$ decreased to $7.18 \pm 3.34$ at 480 hours PT (Table III).

The concentration of DA in kidneys $\left(8.00 \pm 0.46^{\mathrm{a}}\right)$ of dogs in the group treated with DA and OXY-LA was significantly higher $(\mathrm{P}<0.05)$ at 360 hours PT compared to $\left(3.76 \pm 0.32^{\mathrm{b}}\right)$ of the group treated with DA alone but the DA-concentrations did not differ significantly $(\mathrm{P}>0.05)$ at $240 \quad \mathrm{PT}$ and 480 hours PT between the groups though values in the dogs treated with DA plus OXY-LA $\left(9.07 \pm 0.06^{\mathrm{a}}\right.$ and $\left.2.53 \pm 1.31^{\mathrm{a}}\right)$ still remained slightly higher than $6.38 \pm 0.46^{\mathrm{a}}$ and $1.23 \pm 0.39^{\mathrm{a}}$ of the group treated with DA alone (Table IV).

There was no significant difference $(\mathrm{P}>0.05)$ in concentration of DA in hearts of dogs administered DA plus OXY-LA $\left(13.13 \pm 0.69^{\mathrm{a}}, 2.65 \pm 1.55^{\mathrm{a}}\right.$ and $\left.1.12 \pm 0.30^{\mathrm{a}}\right)$ and those administered DA alone $\left(8.67 \pm 4.44^{\mathrm{a}}, 2.90 \pm 0.95^{\mathrm{a}}\right.$ and $\left.0.48 \pm 0.01^{\mathrm{a}}\right)$. The highest concentrations of DA in the heart in both groups were at 240 hours PT, with the least concentrations at 480 hours PT (Table V).

Elimination half-life of DA was not significantly different $(\mathrm{P}>0.05)$ in the brain, skeletal muscle, liver, kidney and heart of dogs treated with DA alone and in those treated with DA plus OXY-LA (Table VI).

Elimination rate constant varied significantly $(\mathrm{P}<0.05)$ between the two groups in the brain and kidney and did not

Table II. The average diminazene aceturate concentrations $(\mu \mathrm{g} / \mathrm{g})$ in the skeletal muscle of dogs treated with diminazene aceturate $(3.5 \mathrm{mg} / \mathrm{kg})$ alone and diminazene aceturate plus oxytetracycline long acting (20mg/kg) combination.

\begin{tabular}{lll}
\hline & \multicolumn{2}{c}{ Concentration $(\mu \mathrm{g} / \mathrm{g})$} \\
$\begin{array}{l}\text { Diminazene } \\
\text { (Hours) }\end{array}$ & Diminazene aceturate & $\begin{array}{l}\text { Oxytetracycline } \\
\text { long acting }\end{array}$ \\
\hline 240 & $15.85 \pm 5.75^{\mathrm{a}}$ & $17.67 \pm 0.26^{\mathrm{a}}$ \\
360 & $10.23 \pm 4.97^{\mathrm{a}}$ & $8.01 \pm 2.39^{\mathrm{a}}$ \\
480 & $5.65 \pm 3.81^{\mathrm{a}}$ & $5.85 \pm 2.65^{\mathrm{a}}$ \\
\hline
\end{tabular}

Different superscript at same row shows significantly difference at $P<0.05$

Table III. The average diminazene aceturate concentrations $(\mu \mathrm{g} / \mathrm{g})$ in the liver of dogs treated with diminazene aceturate $(3.5 \mathrm{mg} / \mathrm{kg})$ alone and diminazene aceturate plus oxytetracycline long acting $(20 \mathrm{mg} / \mathrm{kg})$ combination.

\begin{tabular}{lll}
\hline \multicolumn{2}{c}{ Concentration $(\mu \mathrm{g} / \mathrm{g})$} \\
Dime & $\begin{array}{l}\text { Diminazene } \\
\text { aceturate }\end{array}$ & $\begin{array}{l}\text { Oxytetracycline } \\
\text { long acting }\end{array}$ \\
\hline 240 & $12.91 \pm 2.71^{\mathrm{a}}$ & $8.58 \pm 0.54^{\mathrm{a}}$ \\
360 & $15.12 \pm 3.44^{\mathrm{a}}$ & $8.07 \pm 0.55^{\mathrm{a}}$ \\
480 & $7.18 \pm 3.34^{\mathrm{a}}$ & $5.62 \pm 0.48^{\mathrm{a}}$ \\
\hline Different superscript at same row shows significantly \\
difference at $\mathrm{P}<0.05$
\end{tabular}


vary in other tissues (Table VII).

Table IV. The average diminazene aceturate concentrations $(\mu \mathrm{g} / \mathrm{g})$ in the kidney of dogs treated with diminazene aceturate $(3.5 \mathrm{mg} / \mathrm{kg})$ alone and diminazene aceturate plus oxytetracycline long acting $(20 \mathrm{mg} / \mathrm{kg})$ combination

\begin{tabular}{|c|c|c|}
\hline \multirow[b]{2}{*}{$\begin{array}{l}\text { Time } \\
\text { (Hours) }\end{array}$} & \multicolumn{2}{|c|}{ Concentration $(\mu \mathrm{g} / \mathrm{g})$} \\
\hline & Diminazene aceturate & $\begin{array}{l}\text { Diminazene } \\
\text { Oxytetracycline } \\
\text { long acting }\end{array}$ \\
\hline 240 & $6.38 \pm 0.46^{\mathrm{a}}$ & $9.07 \pm 0.06^{\mathrm{a}}$ \\
\hline 360 & $3.76 \pm 0.32^{b}$ & $8.00 \pm 0.60^{\mathrm{a}}$ \\
\hline 480 & $1.23 \pm 0.39^{\mathrm{a}}$ & $2.53 \pm 1.31^{\mathrm{a}}$ \\
\hline
\end{tabular}

Different superscript at same row shows significantly difference at $P<0.05$

DISCUSSION

Table V. The average diminazene aceturate concentrations $(\mu \mathrm{g} / \mathrm{g})$ in the heart of dogs treated with diminazene aceturate $(3.5 \mathrm{mg} / \mathrm{kg})$ alone and diminazene aceturate plus oxytetracycline long acting (20mg/kg) combination.

\begin{tabular}{|c|c|c|c|c|}
\hline \multicolumn{5}{|c|}{ Concentration $(\mu \mathrm{g} / \mathrm{g})$} \\
\hline $\begin{array}{l}\text { Time } \\
\text { (Hours) }\end{array}$ & \multicolumn{2}{|c|}{ Diminazene aceturate } & \multicolumn{2}{|c|}{$\begin{array}{l}\text { Diminazene }+ \\
\text { Oxytetracycline } \\
\text { long acting }\end{array}$} \\
\hline 240 & \multicolumn{2}{|c|}{$8.67 \pm 4.44^{\mathrm{a}}$} & \multicolumn{2}{|c|}{$13.13 \pm 0.69^{\mathrm{a}}$} \\
\hline 360 & \multicolumn{2}{|c|}{$2.90 \pm 0.95^{\mathrm{a}}$} & \multicolumn{2}{|c|}{$2.65 \pm 1.55^{\mathrm{a}}$} \\
\hline 480 & \multicolumn{2}{|c|}{$0.48 \pm 0.01^{\mathrm{a}}$} & \multicolumn{2}{|c|}{$1.12 \pm 0.30^{\mathrm{a}}$} \\
\hline \multirow{2}{*}{\multicolumn{5}{|c|}{$\begin{array}{l}\text { Different superscript at same row shows significantly } \\
\text { difference at } P<0.05 \\
\text { The results of the present study showed the presence of DA } \\
\text { Table VI: Elimination Half Lives (T1/2/ hr) of } \\
\text { Diminazene aceturate in various tissues of Nigerian } \\
\text { indigenous Dogs treated with Diminazene aceturate } \\
\text { alone and Diminazene aceturate plus oxytetracycline } \\
\text { long acting(LA) }\end{array}$}} \\
\hline & & & & \\
\hline \multicolumn{2}{|c|}{ Tissues } & \multicolumn{2}{|c|}{$\begin{array}{l}\text { Diminazene } \\
\text { aceturate }\end{array}$} & $\begin{array}{c}\text { Diminazene } \\
\text { aceturate+ oxytet } \\
\text { LA } \\
\end{array}$ \\
\hline \multicolumn{2}{|c|}{ Liver } & \multicolumn{2}{|c|}{$295.07 \pm 124.78^{\mathrm{a}}$} & $397.50 \pm 204.93^{\mathrm{a}}$ \\
\hline \multicolumn{2}{|c|}{ Kidney } & \multicolumn{2}{|c|}{$103.85 \pm 24.53^{\mathrm{a}}$} & $281.30 \pm 86.25^{\mathrm{a}}$ \\
\hline \multicolumn{2}{|c|}{ Heart } & \multicolumn{2}{|c|}{$0.48 \pm 0.01^{\mathrm{a}}$} & $1.12 \pm 0.30^{\mathrm{a}}$ \\
\hline \multicolumn{2}{|c|}{ Brain } & \multicolumn{2}{|c|}{$238.92 \pm 38.42^{\mathrm{a}}$} & $102.83 \pm 41.26^{\mathrm{a}}$ \\
\hline \multicolumn{2}{|c|}{ Skeletal muscle } & \multicolumn{2}{|c|}{$149.47 \pm 51.76^{\mathrm{a}}$} & $148.83 \pm 83.38^{\mathrm{a}}$ \\
\hline
\end{tabular}

Different superscript at same row shows significantly difference at $P<0.05$ in all the organs investigated that include brain, skeletal muscle, kidney, liver and heart in the DA alone group and DA combination with OXY-LA and it persisted up to 20 days (480 hours) post treatment. Though, variation in DA concentration occurred between the organs and reduced significantly with time post treatment. The brain of dogs given DA with OXY-LA have the highest DA concentration $\left(19.71 \pm 1.31^{\mathrm{a}}\right)$ and minimum level $\left(0.71 \pm 0.30^{\mathrm{b}}\right)$ was observed in brain of dogs administered DA alone at 480 hours. The shortest time PT of 240 hours showed highest DA concentration in most organs while the longest, 480 hours PT, had the minimum DA residual in organs examined. It is important to note that there was a gradual elimination of DA in all the organs as time progressed except the liver with a rise after a decline which could be due to entero-hepatic recirculation.

The reason for the highest concentrations of Diminazene occurrence in the brain and skeletal muscles of dogs administered Diminazene aceturate in combination with Oxytetracycline long acting could be the magnesium oxide $(\mathrm{MgO})$ Nanoparticle that are contained in OXY-LA formulation (Aguiar, et al., 1987). Short- and long-acting, injectable formulations are commonly used at the dose rate of $10 \mathrm{mg} / \mathrm{kg}$ and $20 \mathrm{mg} / \mathrm{kg}$, respectively. The long acting formulation is usually administered once and is expected to maintain a therapeutic plasma concentration for 3 to 4 days, whereas the short- acting formulation is recommended for daily use for 3 to 4 days to maintain therapeutic plasma concentrations (Toutain \& Raynaud, 1985). The long acting formulation is made long acting by addition of magnesium oxide and this stabilizes oxytetracycline and enables one injection of it to maintain a therapeutic plasma concentration for 3 to 4 days. So when the DA and OXY-LA interact in the blood, it is possible that $\mathrm{MgO}$ also stabilizes DA instead of OXY-LA alone. Since $\mathrm{MgO}$ has the lowest molecular

Table VII: Elimination rate constant $\left(\beta h^{-1}\right)$ of Diminazene aceturate in various tissues of Nigerian indigenous Dogs treated withDiminazene aceturate alone and Diminazene aceturate plus oxytetracycline long acting(LA)

\begin{tabular}{lll}
\hline Tissues & $\begin{array}{l}\text { Diminazene } \\
\text { aceturate }\end{array}$ & $\begin{array}{l}\text { Diminazene } \\
\text { oxytet LA }\end{array}$ \\
\hline Liver & $0.003 \pm 0.001$ & $0.003 \pm 0.002$ \\
Kidney & $0.007 \pm 0.002^{\mathrm{a}}$ & $0.003 \pm 0.001$ \\
Heart & $0.070 \pm 0.060$ & $0.011 \pm 0.001$ \\
Brain & $0.0025 \pm 0.000$ & $0.008 \pm 0.003^{\mathrm{a}}$ \\
Skeletal muscle & $0.005 \pm 0.002$ & $0.007 \pm 0.004$
\end{tabular}

Different superscript at same row shows significantly difference at $P<0.05$

weight of $40.304 \mathrm{~g} / \mathrm{mol}$, (Haynes, 2011) among them (DA 
and OXY-LA) and high affinity to pass through the blood brain barrier (Norrby, 1985), it enhances penetration of DA through the blood-brain barrier and its accumulation by stabilizing it too. Clinically, this is important because the enhanced accumulation of DA in brain could lead to elimination of sequestered trypanosomes in the brain. It may also be responsible for the nervous signs often reported as side effects of treating dogs with DA and OX-LA.

Higher concentrations of Diminazene in the skeletal muscles up to day-20 (480 hours) also suggests delay in elimination of Diminazene by Oxytetracycline long acting. This contradicts the report of Eke et al. (2017) whose study detected DA at 240 hours only.

The significant difference $(\mathrm{P}<0.05)$ noticed in the average concentration of Diminazene between the two groups in the kidney agrees with the report by Eke et al. (2017), that Diminazene was detectable in the kidney up to 480hours PT. This also suggests that Oxytetracycline-long acting has ability to protect diminazene from being rapidly metabolized/eliminated, hence the accumulation.

Increase in the concentration of Diminazene in the liver from $12.91 \pm 2.71$ at 240 hours PT to $15.12 \pm 3.34$ at 360 hours PT and the decrease to $7.18 \pm 3.34$ at 480 hours PT in the group treated Diminazene aceturate alone could be due to enterohepatic re-circulation of Diminazene aceturate. Naidoo et al. (2009) also observed this in their study.

There was no significant differences $(\mathrm{P}>0.05)$ were observed between the two groups. Increase in the concentration of Diminazene in the liver from $12.91 \pm 2.71$ at 240 hours PT to $15.12 \pm 3.34$ at 360 hours PT and the decrease to $7.18 \pm 3.34$ at 480 hours PT in the group treated Diminazene aceturate alone could be due to entero-hepatic re-circulation of Diminazene aceturate. Naidoo et al. (2009) also observed this in their study.

There was no significant difference $(P>0.05)$ in the average concentration of Diminazene aceturate in the heart between the two groups though the values of diminazene were higher in the group treated with DA plus OXY-LA than DA alone. This could mean that DA either given alone or in combination with OXY-LA does not affect the heart.

The elimination half-lives of DA in various tissues such as the brain, skeletal muscle, liver, kidney and heart of both the group on DA alone and the group of DA plus OXY-LA were not significantly different $(\mathrm{P}>0.05)$ while elimination rate constants were significantly different $(\mathrm{P}<0.05)$ in the brain and kidney only. However the value of elimination half-life of Diminazene in the brain was very low in the group treated with the combination of Diminazene aceturate and Oxytetracycline long acting in comparison with the group treated with Diminazene aceturate alone thus suggesting that Oxytetracycline long acting delays the elimination of Diminazene in the brain and this makes the drug to stay longer and exact a prolonged effects than normal. It made the normal dose of diminazene to act like over dose, hence the nervous signs which are diminazene toxicity.

This appears to explain the toxic effects or central nervous system signs often observed when the two drugs are used concurrently in treatment of dogs (Donghyun et al., 2014). The presence of Diminazene residues in significant quantities in brain, skeletal muscles and liver of dogs treated with DA/OXY-LA combination between $10^{\text {th }}$ day PT (240 hours) to $20^{\text {th }}$ day PT (480 hours) in brain, may mean that Diminazene was not eliminated within 20 days in both groups and this should be taken into consideration in estimation of withdrawal period of DA in treated animals.

These findings suggest that OXY-LA may have enhanced distribution/accumulation of DA in various tissues of dogs and this effect enhances the therapeutic efficacy of DA. This may imply that it is the Magnesium oxide-Nanoparticles OXY-LA that are responsible for these effects because a study by Jennings (1987) with short acting Oxytetracycline formulation in combination with DA did not report such enhanced distribution or delayed elimination of Diminazene aceturate. There was also no report of nervous signs as side effects.

In a study by Youssef et al. (2010) in goats, he assayed OXY-LA and deduced that concurrent administration of OXY--LA and DA lowered/reduced efficacy of OXY-LA while in this study OXY-LA enhanced accumulation and therapeutic plasma concentrations of DA. This also suggests that the stabilizing agent (adjuvant) meant for OXY-LA alone shared the effect with DA.

\section{CONCLUSION}

OXY-LA appears to cause increased distribution, accumulation/higher tissue levels and higher bioavailability of DA in dogs. Meanwhile the acceptable daily intake (ADI) of Diminazene for a $5 \mathrm{~kg}$ dog is $1 \mathrm{mg}$. Since the value of the residues in all the tissues if calculated is not up to $1 \mathrm{mg}$, we suggest that the withdrawal period of diminazene aceturate should be between 20 days to 27 days post drug administration such that interaction between the two drugs enhances the distribution/delivery of diminazene across physiological barriers and reduces elimination half-life of DA sequel to which are toxicity signs. This interaction between DA and OXY-LA can be exploited to develop effective treatment for cerebral infections.

\section{CONFLICT OF INTEREST}

Authors have no conflict of interest.

\section{REFERENCES}

Adir, J., (1975). Enterohepatic circulation of tetracycline in rats. Journal of Pharmaceutical Science, 64, 18471850 .

Aguiar, A.J, Armstrong, W.A, Desai, S.J., (1987). Development of oxytetracycline long-acting 
injectable. Journal of Controlled Release, 6 (1), 375-385

Baeder, Schulz \& Kramer, (1975). Eine Vertraglichkeitsprufung von Berenil-diazeturat un Wistar -Ratten uber 3, 6 and 9 montae bei orale verbreichung im taglichen futter und mit der sunder. Hoechst Toxicology Research Report, 28, 1.

Brack C, Delain E, Riou G \& Festy B., (1972). Molecular organization of the kinetoplast DNA of Trypanosoma cruzi treated with berenil, a DNA interacting drug. Journal of Ultrastructure Research, 39, 568-579.

Bywater, R.J. (1991). Veterinary Applied Pharmacology and Therapeutics; Bailliere Tindal: London, UK.

Chopra, I. \& Roberts, M.(2001). Tetracycline antibiotics: Mode of action, applications, molecular biology, and epidemiology of bacterial resistance. Microbiology Molecular Biology Review, 65, 232260.

Daniel, W. W. (2010). Biostatistics: basic Concepts and Methodology for the Health Sciences, $9^{\text {th }}$ ed., Willey New Delhi.

DaSilva, A.S., Zanette, R.A., Wolkmer, P., Costa, M.M., Garcia, H.A., Lopes, S.T.A., Santurio, J.M., Teixeira, M.M.G. \& Monteiro, S.G. (2009). Diminazene aceturate in the control of Trypanosoma evansi infection in cats. Veterinary Parasitology, 165, 47-50.

Donghyum, H., Won-Kyoung, Y and Changbaig, H. (2014). Cerebellar encephalopathy from diminazene aceturate (Berenil) toxicity in a dog. Korean journal of Veterinary Research, 54 (3), 193-196.

Eke, I.G., Eze, U.U., Ezeudu, T.A., Ezeh, I.O., Anaga, A.O. \& Onyeyili, P.A. (2017). Diminazene aceturate residues in tissues of dogs treated with secnidazolediminazene aceturate combination and with diminazene aceturate alone. Sokoto Journal of Veterinary Sciences, 15, 16 - 20..

Escudero, E.; Carceles, C.M. \& Serrano, J.M. (1994). Pharmacokinetics of oxytetracycline in goats: Modifications induced by a long-acting formulation. Veterinary Record, 135, 548-552.

Gonzalez, V.M., Perez, J.M. \& Alonso, C. (1997). The berenil ligand directs the DNA binding of the cytotoxic drug Pt-berenil. Journal of Inorganic Biochemistry, 68, 283-287.

Haaf T, Feichtinger W, Guttenbach M, Sanchez L, Muller CR and Schmid M. (1989). Berenil-induced undercondensation in human heterochromatin. Cytogenetic Cell Genetic, 50, 27-33.

Jennings, F.W. (1987). Effect of tetracycline administration on the efficacy of diminazene aceturate therapy and prophylaxis in Trypanosoma brucei infections of mice. Elsevier: Research in Veterinary medicine. 43, (2), 173-176.

Koshiishi, I., Mamura Y., Liu J. \& Imanari T. (1998). Evaluation of an acidic deproteinization for the measurement of ascorbate and dehydroascorbate in plasma samples. Clinical Chemical, 63, 868.

Miller, D.M., Swan, G.E., Lobetti, R.G. \& Jacobson, L.S. (2005). The pharmacokinetics of dimina- zene aceturate after intramuscular administration in healthy dogs. Journal of the South African Veterinary Association. 76, 146-150.

Norrby, S. R. 1985. Role of cephalosporins in the treatment of bacterial meningitis in adults. Overview with special emphasis on ceftazidime. Amsterdam Journal of Medicine, 79, 56-61

Onyeyili P A, \& Anika, S.M. (1991) Diminazene aceturate residues in the tissues of healthy, Trypanosoma congolense and Trypanosoma brucei brucei infected dogs. British Veterinary Journal, 147, 155162.

Peregrine, A.S. \& Mamman, M. (1993). Pharmacology of diminazene: a review. Acta Tropical, 4, 185-203.

Poot, M., Kausch, K., Kohler, J., Haaf, T. \& Hoehn, H. (1990). The minor- groove binding DNA-ligands netropsin, distamycin A and berenil cause polyploidisation via impairment of the $\mathrm{G} 2$ phase of the cell cycle. Cell Structure Function, 15, 151157.

Rang, H.P., Dale, M.M. \& Ritter, J.M. (1996). Pharmacology, Third edition. Churchill Livingstone, London. Pp 772.

Rashid, H.B., Chaudhry, M., Rashid, H., Pervez, K., Khan, M.A. \& Mahmood, A.K. (2008). Comparative efficacy of diminazene diaceturate and diminazene aceturate for the treatment of babesiosis in horses. Tropical Animal Health and Production, 40, 463467.

Riou, G. \& Benard, J. (1980). Berenil induces the complete loss of kinetoblast DNA sequences in Trypanosoma equiperdum. Biochemical Biophysical Research Communication, 96, 350-354.

Toutain, P.L., Raynaud, J.P. (1983). Pharmacokinetics of oxytetracycline in young cattle: comparison of conventional versus long-acting formulations. Amsterdam Journal of Veterinary Research, 44(7):1203-1209.

Youssef, S. A., Aziza, A., Amer, M. M., Galal, A. M. \& Constable, P. D. (2010). Effect of diminazine aceturate on the pharmacokinetic of a long acting oxytetracycline formulation in lactating goats. Veterinary Medical Journal Giza, 58 (1), 31-48

Article history: Received: May 12, 2021, Revised: August 12, 2021, Accepted: August 14, 2021 